Internat. J. Math. \& Math. Sci.

Vol. 23, No. 10 (2000) 697-701

S016117120000260X

(c) Hindawi Publishing Corp.

\title{
UNIVALENCE OF CERTAIN INTEGRAL OPERATORS
}

\section{VIRGIL PESCAR and SHIGEYOSHI OWA}

(Received 1 December 1998)

AвSTRACT. We study some integral operators and determine conditions for the univalence of these integral operators.

Keywords and phrases. Integral operator, univalence.

2000 Mathematics Subject Classification. Primary 30C45.

1. Introduction. Let $A$ be the class of the functions $f$ which are analytic in the unit $\operatorname{disc} U=\{z \in C ;|z|<1\}$ and $f(0)=f^{\prime}(0)-1=0$.

We denote by $S$ the class of the functions $f \in A$ which are univalent in $U$.

Many authors studied the problem of integral operators which preserve the class $S$. In this sense an important result is due to Pfaltzgraff [4].

THEOREM 1.1 [4]. If $f$ is univalent in $U, \alpha$ a complex number and $|\alpha| \leq 1 / 4$, then the function

$$
G_{\alpha}(z)=\int_{0}^{z}\left[f^{\prime}(\xi)\right]^{\alpha} d \xi
$$

is univalent in $U$.

THEOREM 1.2 [3]. If the function $g \in S$ and $\alpha$ is a complex number, $|\alpha| \leq 1 /(4 n)$, then the function defined by

$$
G_{\alpha, n}(z)=\int_{0}^{z}\left[g^{\prime}\left(u^{n}\right)\right]^{\alpha} d u
$$

is univalent in $U$ for all positive integer $n$.

2. Preliminary results. We need the following theorems.

TheOREM 2.1 [2]. Let $\alpha$ be a complex number, $\operatorname{Re} \alpha>0$ and $f \in A$. If

$$
\frac{1-|z|^{2 \operatorname{Re} \alpha}}{\operatorname{Re} \alpha}\left|\frac{z f^{\prime \prime}(z)}{f^{\prime}(z)}\right| \leq 1
$$

for all $z \in U$, then for any complex number $\beta, \operatorname{Re} \beta \geq \operatorname{Re} \alpha$ the function

$$
F_{\beta}(z)=\left[\beta \int_{0}^{z} u^{\beta-1} f^{\prime}(u) d u\right]^{1 / \beta}
$$

is in the class $S$. 
THEOREM 2.2 [1]. If the function $g$ is regular in $U$ and $|g(z)|<1$ in $U$, then for all $\xi \in U$ and $z \in U$ the following inequalities hold:

$$
\begin{gathered}
\left|\frac{g(\xi)-g(z)}{1-\overline{g(z)} g(\xi)}\right| \leq\left|\frac{\xi-z}{1-\bar{z} \xi}\right| \\
\left|g^{\prime}(z)\right| \leq \frac{1-|g(z)|^{2}}{1-|z|^{2}},
\end{gathered}
$$

the equalities hold only in the case $g(z)=\epsilon(z+u) /(1+\bar{u} z)$, where $|\epsilon|=1$ and $|u|<1$.

REMARK 2.3 [1]. For $z=0$, from inequality (2.3)

$$
\left|\frac{g(\xi)-g(0)}{1-\overline{g(0)} g(\xi)}\right| \leq|\xi|
$$

and, hence

$$
|g(\xi)| \leq \frac{|\xi|+|g(0)|}{1+|g(0)||\xi|} .
$$

Considering $g(0)=a$ and $\xi=z$,

$$
|g(z)| \leq \frac{|z|+|a|}{1+|a||z|}
$$

for all $z \in U$.

SCHWARZ LEMMA [1]. If the function $g$ is regular in $U, g(0)=0$ and $|g(z)| \leq 1$ for all $z \in U$, then the following inequalities hold:

$$
|g(z)| \leq|z|
$$

for all $z \in U$, and $\left|g^{\prime}(0)\right| \leq 1$, the equalities (in inequality (2.8) for $z \neq 0$ ) hold only in the case $g(z)=\epsilon z$, where $|\epsilon|=1$.

\section{Main results}

THEOREM 3.1. Let $\alpha, \gamma$ be complex numbers, $\operatorname{Re} \alpha=a>0$ and $g \in A$.

If

$$
\left|\frac{g^{\prime \prime}(z)}{g^{\prime}(z)}\right| \leq \frac{1}{n}
$$

for all $z \in U$ and

$$
|\gamma| \leq \frac{n+2 a}{2}\left(\frac{n+2 a}{n}\right)^{n / 2 a},
$$

then for any complex number $\beta, \operatorname{Re} \beta \geq a$, the function

$$
G_{\beta, \gamma, n}(z)=\left\{\beta \int_{0}^{z} u^{\beta-1}\left[g^{\prime}\left(u^{n}\right)\right]^{\gamma} d u\right\}^{1 / \beta}
$$

is in the class $S$ for all $n \in N^{*}-\{1\}$. 
Proof. Let us consider the function

$$
f(z)=\int_{0}^{z}\left[g^{\prime}\left(u^{n}\right)\right]^{\gamma} d u .
$$

The function

$$
p(z)=\frac{1}{|\gamma|} \frac{f^{\prime \prime}(z)}{f^{\prime}(z)}
$$

where the constant $|\gamma|$ satisfies the inequality (3.2), is regular in $U$.

From (3.4) and (3.5), we obtain

$$
p(z)=\frac{\gamma}{|\gamma|}\left[\frac{n z^{n-1} g^{\prime \prime}\left(z^{n}\right)}{g^{\prime}\left(z^{n}\right)}\right] .
$$

Using (3.1) and (3.6) we obtain

$$
|p(z)|<1
$$

for all $z \in U$. For $z=0$ we have $p(0)=0$.

From (3.6) and Schwarz lemma it results that

$$
\frac{1}{|\gamma|}\left|\frac{f^{\prime \prime}(z)}{f^{\prime}(z)}\right| \leq|z|^{n-1} \leq|z|
$$

for all $z \in U$, and hence

$$
\left(\frac{1-|z|^{2 a}}{a}\right)\left|\frac{z f^{\prime \prime}(z)}{f^{\prime}(z)}\right| \leq|\gamma|\left(\frac{1-|z|^{2 a}}{a}\right)|z|^{n}
$$

Let us consider $Q:[0,1] \rightarrow R, Q(x)=\left(\left(1-x^{2 a}\right) / a\right) x^{n}, x=|z|$. We have

$$
Q(x) \leq \frac{2}{n+2 a}\left(\frac{n}{n+2 a}\right)^{n / 2 a}
$$

for all $x \in[0,1]$. From (3.2), (3.9), and (3.10) we obtain

$$
\left(\frac{1-|z|^{2 a}}{a}\right)\left|\frac{z f^{\prime \prime}(z)}{f^{\prime}(z)}\right| \leq 1
$$

for all $z \in U$. Then, from (3.11) and Theorem 2.1 it follows that the function $G_{\beta, \gamma, n}$ is in the class $S$.

THEOREM 3.2. Let $\alpha, \gamma$ be complex numbers, $\operatorname{Re} \alpha=b>0$ and the function $g \in A$, $g(z)=z+a_{2} z^{2}+\cdots \cdot$ If

$$
\left|\frac{g^{\prime \prime}(z)}{g^{\prime}(z)}\right|<1
$$

for all $z \in U$ and the constant $|\gamma|$ satisfies the condition

$$
|\gamma| \leq \frac{1}{\max _{|z| \leq 1}\left[\left(\left(1-|z|^{2 b}\right) / b\right)|z|\left(\left(|z|+2\left|a_{2}\right|\right) /\left(1+2\left|a_{2}\right||z|\right)\right)\right]}
$$


then for any complex number $\beta, \operatorname{Re} \beta \geq b$ the function

$$
G_{\beta, \gamma}(z)=\left\{\beta \int_{0}^{z} u^{\beta-1}\left[g^{\prime}(u)\right]^{\gamma} d u\right\}^{1 / \beta}
$$

is in the class $S$.

Proof. Let us consider the function

$$
f(z)=\int_{0}^{z}\left[g^{\prime}(u)\right]^{\gamma} d u .
$$

The function

$$
h(z)=\frac{1}{|\gamma|} \frac{f^{\prime \prime}(z)}{f^{\prime}(z)}
$$

where the constant $|\gamma|$ satisfies the inequality (3.13), is regular in $U$.

From (3.15) and (3.16) we have

$$
h(z)=\frac{\gamma}{|\gamma|} \frac{g^{\prime \prime}(z)}{g^{\prime}(z)} .
$$

Using (3.12) and (3.17) we obtain

$$
|h(z)|<1
$$

for all $z \in U$ and $|h(0)|=2\left|a_{2}\right|$.

Remark 2.3 applied to the function $h$ gives

$$
\frac{1}{|\gamma|}\left|\frac{f^{\prime \prime}(z)}{f^{\prime}(z)}\right| \leq \frac{|z|+2\left|a_{2}\right|}{1+2\left|a_{2}\right||z|}
$$

for all $z \in U$.

From (3.19) we obtain

$$
\frac{1-|z|^{2 b}}{b}\left|\frac{z f^{\prime \prime}(z)}{f^{\prime}(z)}\right| \leq|\gamma| \frac{1-|z|^{2 b}}{b}|z| \frac{|z|+2\left|a_{2}\right|}{1+2\left|a_{2}\right||z|}
$$

for all $z \in U$. Hence, we have

$$
\frac{1-|z|^{2 b}}{b}\left|\frac{z f^{\prime \prime}(z)}{f^{\prime}(z)}\right| \leq|\gamma| \max _{|z| \leq 1}\left[\frac{1-|z|^{2 b}}{b}|z| \frac{|z|+2\left|a_{2}\right|}{1+2\left|a_{2}\right||z|}\right] .
$$

From (3.13) and (3.21) we obtain

$$
\frac{1-|z|^{2 b}}{b}\left|\frac{z f^{\prime \prime}(z)}{f^{\prime}(z)}\right| \leq 1
$$

for all $z \in U$. From Theorem 2.1, it follows that the function $G_{\beta, \gamma}$ defined by (3.14) is in the class $S$. 


\section{REFERENCES}

[1] Z. Nehari, Conformal Mapping, McGraw-Hill Book Co., Inc., New York, Toronto, London, 1952. MR 13,640h. Zbl 048.31503.

[2] N. N. Pascu, An improvement of Becker's univalence criterion, Proceedings of the Commemorative Session: Simion Stoïlow (Braşov, 1987) (Braşov), Univ. Braşov, 1987, pp. 43-48. MR 90j:30033. Zbl 666.30012.

[3] N. N. Pascu and V. Pescar, On the integral operators of Kim-Merkes and Pfaltzgraff, Mathematica (Cluj) 32(55) (1990), no. 2, 185-192. MR 93d:30034. Zbl 761.30011.

[4] J. A. Pfaltzgraff, Univalence of the integral of $f^{\prime}(z)^{\lambda}$, Bull. London Math. Soc. 7 (1975), no. 3, 254-256. MR 52\#8410. Zbl 316.30012.

Pescar: Department of Mathematics, Faculty of Science, “Transilvania” University OF BRAŞOV, 2200 BRAŞOV, ROMANIA

E-mail address: vi rgi 1 pescar@hotmai 1 .com

OWA: Department of Mathematics, Kinki University, Higashi-OSAKA, OSAKa 577-8502, JAPAN 


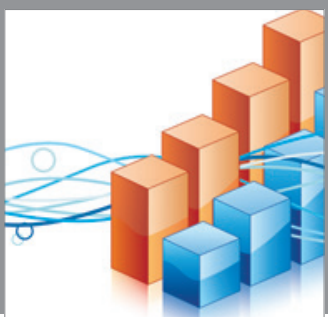

Advances in

Operations Research

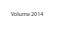

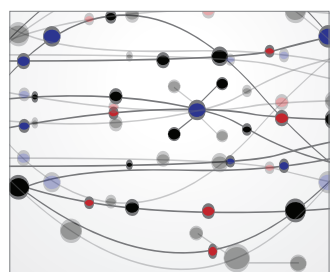

\section{The Scientific} World Journal
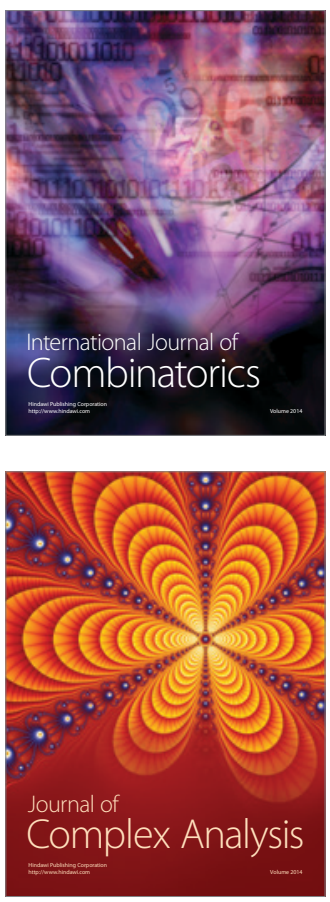

International Journal of

Mathematics and

Mathematical

Sciences
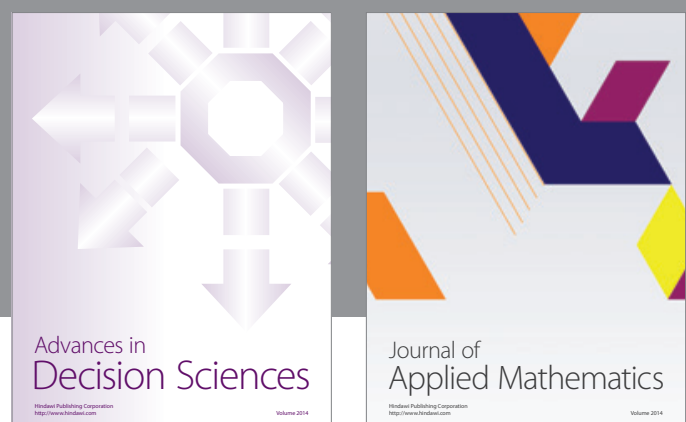

Journal of

Applied Mathematics
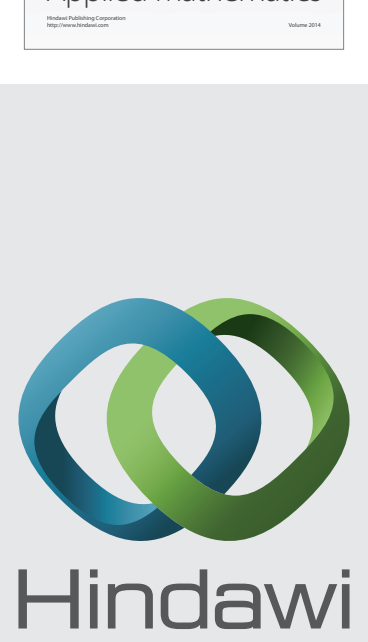

Submit your manuscripts at http://www.hindawi.com
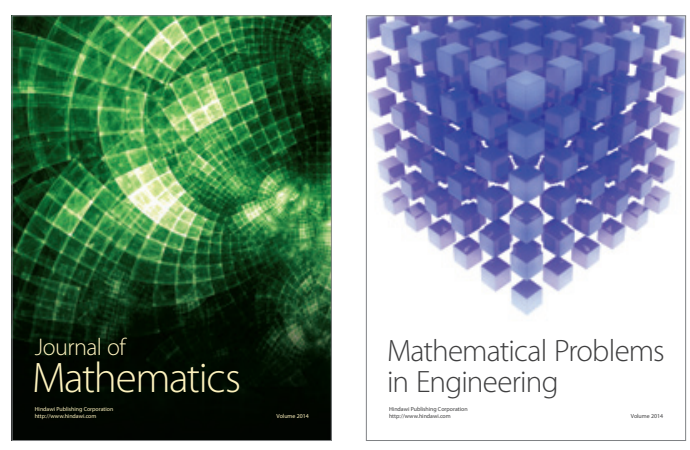

Mathematical Problems in Engineering
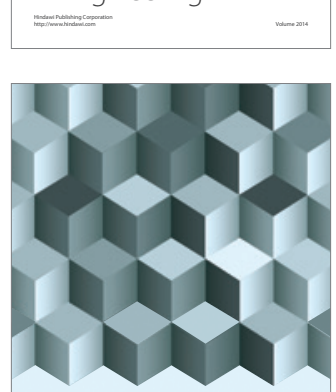

Journal of

Function Spaces
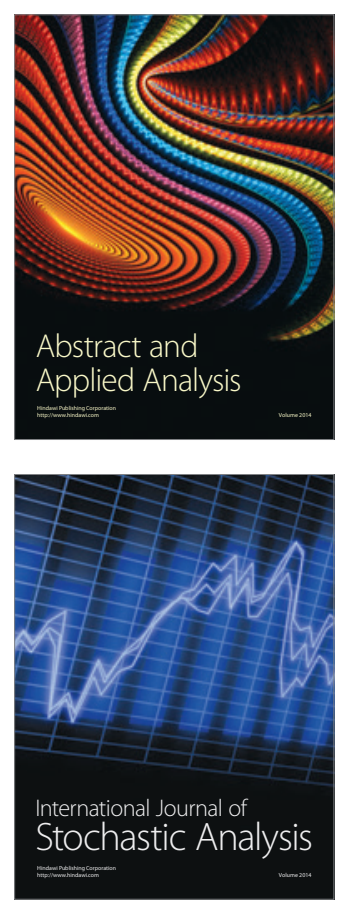

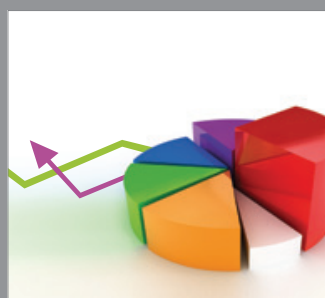

ournal of

Probability and Statistics

Promensencen
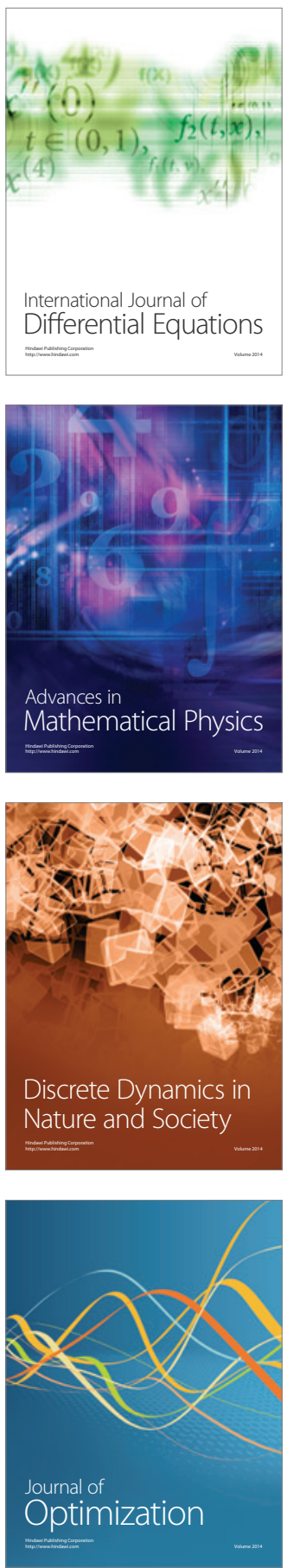